\section{Kidney \\ Blood Pressure \\ Research}

Kidney Blood Press Res 2013;37:24-32

DOI: 10.1159/000343397

Published online: IVarch 06, 2013

(C) 2013 S. Karger AG, Base

www.karger.com/kbr

Accepted: February 13, 2013

1423-0143/13/0371-0024\$38.00/0

This is an Open Access article licensed under the terms of the Creative Commons AttributionNonCommercial-NoDerivs 3.0 License (http://www.karger.com/OA-license), applicable to the online version of the article only. Distribution for non-commercial purposes only.

Review

\title{
Emerging Effects of Sevelamer in Chronic Kidney Disease
}

\author{
Ryota Ikee Masataka Tsunoda $^{\mathrm{b}, \mathrm{c}}$ Naomi Sasaki ${ }^{\mathrm{b}}$ Naritsugu Sato ${ }^{\mathrm{b}, \mathrm{c}}$ \\ Nobuo Hashimoto ${ }^{b}$ \\ aDepartment of Nephrology and Dialysis, H. N. Medic Kitahiroshima, Kitahiroshima, Japan; \\ ${ }^{b}$ Department of Nephrology and Dialysis, H. N. Medic, Sapporo, Japan; 'Department of Nephrology \\ and Dialysis, H. N. Medic Sapporo-Higashi, Sapporo, Japan
}

\section{Key Words}

Cardiovascular disease $\cdot$ CKD-MBD $\bullet$ Phosphate binder $•$ Sevelamer

\begin{abstract}
Sevelamer, a non-absorbable anion exchange resin, is used to control hyperphosphatemia in chronic kidney disease (CKD) by binding to dietary phosphate in the gastrointestinal tract. Lipidlowering effect is a widely recognized pleiotropic effect of sevelamer. In addition, many studies have reported that sevelamer leads to reduced vascular calcification compared with calciumcontaining phosphate binders, which is attributed to the improved lipid profiles and decreased calcium load. In addition, recent studies have suggested novel pleiotropic effects on bone structure, inflammation, oxidative stress, anemia, fetuin-A, and trace element metabolism in CKD patients. All of these effects have the potential to suppress the development/progression of cardiovascular lesions and reduce mortality. This review summarizes novel findings from recent studies and discusses the potential pleiotropic effects of sevelamer on non-traditional cardiovascular risk factors in CKD patients.
\end{abstract}

Copyright $@ 2013$ S. Karger AG, Basel

\section{Introduction}

Disturbances in mineral metabolism and bone disease are common complications of chronic kidney disease (CKD) and lead to an increased risk of cardiovascular morbidity and mortality [1]. The term 'CKD-mineral bone disorder (CKD-MBD)' is increasingly widely recognized. Phosphate binders, vitamin D receptor activators (VDRA), and calcimimetics play pivotal roles in the management of CKD-MBD. Recently, the pleiotropic effects of these agents have been widely examined. Among these agents, VRDA seem to attract the most 


\section{Kidney Blood Pressure Research}

\begin{tabular}{l|l}
\hline Kidney Blood Press Res 2013;37:24-32 \\
\hline DOI: 10.1159/000343397 & o 2013 S. Karger AG, Basel
\end{tabular}

Publisned online: Viarch 06, 2013

www.karger.com/kbr

Ikee/Tsunoda/Sasaki/Sato/Hashimoto: Emerging Effects of Sevelamer

attention. The reported pleiotropic effects of VDRA include improvement of proteinuria, immune regulation, the renin-angiotensin system, cardiac function, vascular calcification, and mortality [2]. On the other hand, less attention has been paid to the effects of sevelamer despite its unique characteristics.

Sevelamer is a non-absorbable, calcium-free and aluminum-free anion exchange resin, which binds to dietary phosphate in the gastrointestinal tract. There are two salts of sevelamer, sevelamer hydrochloride and sevelamer carbonate, and the former was used in most previous studies investigating its effects. Early studies have found that sevelamer hydrochloride and calcium-containing phosphate binders produce comparable decreases in serum phosphorus level in patients on hemodialysis (HD) [3, 4]. The calcium-free nature of sevelamer means that it is associated with a reduced incidence of hypercalcemia [4], which allows the safe use of VDRA and better control of secondary hyperparathyroidism. In addition, improvement of lipid profiles by sevelamer is well established [3-5]. Compared with calcium-containing phosphate binders, sevelamer hydrochloride is associated with slow progression of cardiovascular calcification [5-10]. Various mechanisms as well as reduced calcium load and lipid-lowering effect might be responsible for suppression of cardiovascular lesions. Sevelamer binds to not only phosphate but other substances, which would explain its pleiotropic effects.

\section{Effects on cardiovascular disease, mortality and hospitalization}

Many studies have been demonstrated improved cardiovascular function and structure by sevelamer hydrochloride [5-14]. For example, In the RIND study, a randomized trial including 129 incident HD patients, Block et al. compared the progression of coronary and aortic calcification detected by electron beam computed tomography (CT) between sevelamer hydrochloride and calcium-containing phosphate binder [7]. The median increase in calcification score at 18 months was 11 -fold greater in those treated with calciumcontaining phosphate binder compared with those treated with sevelamer $(P=0.01)$. Also in prevalent HD patients, Chertow et al. found similar findings in the Treat-to-Goal study [5]. In 132 prevalent HD patients, Raggi et al. compared the progression of heart valve calcification between sevelamer hydrochloride and calcium-containing phosphate binder in a 1-year follow-up [10]. Heart valve calcification progressed more slowly in the sevelamer group after adjustment for baseline calcification and the time-averaged $\mathrm{Ca} \times \mathrm{P}$ product. On the other hand, 2 randomized trials, the BRiC study including 101 prevalent HD patients [15] and the CARE2 study including 203 prevalent HD patients [16], did not find a significant difference in the progression of vascular calcification between calcium acetate and sevelamer hydrochloride. In the former study, the inconsistent result might be attributable to a higher mortality in the calcium acetate group ( 8 of 49 patients in the calcium acetate group and 1 of 52 patients in the sevelamer group died in a 12-month follow-up). Patients with severe calcification might have been eliminated from the study. In the latter study, the high dropout rate, the higher frequencies of diabetes mellitus and smokers at baseline might be confounding factors.

Regarding the effect of sevelamer on mortality in HD patients, some studies have shown that sevelamer decreases mortality compared with calcium-containing phosphate binders $[14,17,18]$, but others have not $[19,20]$. In the RIND extension study, a randomized trial including 127 incident HD patients, Block et al. showed a trend towards increased mortality in the patients treated with calcium-containing phosphate binders compared with those treated with sevelamer hydrochloride $(P=0.06)$ in a median follow-up of 44 months [17]. After adjustment for multiple factors, the difference in mortality between the groups reached statistical significance $(P=0.02)$. In addition, 2 cohort studies using a propensity-matched method detected decreased mortality in HD patients treated with sevelamer hydrochloride $[14,18]$. In CKD patients not requiring HD, one randomized trial showed lower all-cause mortality in those treated with sevelamer compared with those treated with calcium carbonate [21]. However, the DCOR study, a randomized trial including 2103 prevalent HD 


\section{Kidney Blood Pressure Research}

Ikee/Tsunoda/Sasaki/Sato/Hashimoto: Emerging Effects of Sevelamer

patients, there was no significant difference in all-cause or cause-specific mortality between those treated with sevelamer hydrochloride and those treated with calcium-containing phosphate binders during a follow-up period of 20 months [19]. In addition, secondary analysis of the DCOR study did not detect the benefit of sevelamer in terms of mortality except in the patients aged $\geq 65$ years [20]. The limitation of the DCOR study was that $49.2 \%$ of the subjects were lost to follow-up, and those lost early were only followed for 90 days. The inconsistencies between the results of the RIND study and those of the DCOR study could be attributable to the difference in the follow-up period and patient selection.

Regarding hospitalization, secondary analysis of the DCOR study reported a beneficial effect of sevelamer on all-cause hospitalization compared with calcium-containing phosphate binder [20], but other studies did not [5,19]. As available data are limited, it seems difficult to draw a conclusion.

Thus, the effect of sevelamer on mortality is not conclusive. However, many pieces of evidence suggest that sevelamer has favorable effects on non-traditional cardiovascular risk factors in CKD patients. We discuss this issue and the possibility of improvement of patient's prognosis by sevelamer in the following sections.

\section{Effect on bone structure}

Several studies have shown that sevelamer favorably affects renal bone disease. In a randomized trial including $72 \mathrm{HD}$ patients [6], the patients treated with calcium carbonate showed a significant decrease in trabecular bone density at 24 months after the therapy. In contrast, sevelamer therapy was associated with a significant increase in trabecular bone density. Raggi et al. performed a post-hoc analysis of a 52-week randomized trial comparing sevelamer hydrochloride with calcium acetate in HD patients [22]. In this study, they investigated bone attenuation obtained by CT, which reflects bone mass density. During the study period, the calcium acetate group showed significantly decreased bone attenuation compared with the sevelamer group despite having an increased serum calcium level. Ferreira et al. provided histological support to the results of the aforementioned studies. In a 54-week randomized trial, bone formation determined by bone biopsy increased and trabecular architecture improved in the sevelamer group, but not in the calcium carbonate group [23]. The authors suggested that the higher use of VDRA in the sevelamer group could explain the increased bone formation, but the precise mechanisms remain to be elucidated.

\section{Effect on FGF-23}

Fibroblast growth factor (FGF)-23 is produced by osteocytes and plays an important role in the metabolism of phosphate and vitamin D. Recent studies have shown that increased serum FGF-23 level is associated with left ventricular hypertrophy [24] and mortality [25] in HD patients. Also in an experimental study, FGF-23 induced left ventricular hypertrophy in animal models [26].

Oliveira et al. examined the effect of sevelamer on FGF-23 in a 6-week randomized trial including 40 patients with CKD stage 3 to 4 [27]. After the therapy, the patients treated with sevelamer hydrochloride showed significantly decreased serum FGF-23 level $(P<0.05)$, whereas those treated with calcium acetate $\operatorname{did} \operatorname{not}(P<0.05$ between two groups). Similarly, Yilmaz et al. found a 27.1\%-decrease in serum FGF-23 level at 8 weeks after sevelamer therapy in CKD patients [11]. In HD patients, Brandenburg et al. did not detect improvement of serum FGF-23 level after sevelamer therapy [28]. Although the results regarding the effect of sevelamer on FGF-23 are somewhat inconsistent, the effect would be an issue of increasing interest in CKD patients. 


\section{Kidney Blood Pressure Research}

Ikee/Tsunoda/Sasaki/Sato/Hashimoto: Emerging Effects of Sevelamer

\section{Anti-inflammatory effect}

Several studies have shown that sevelamer improves inflammation marker level. In a randomized trial including 108 HD patients, Ferramosca et al. observed a significant decrease in serum high-sensitivity C-reactive protein (hs-CRP) level in the patients treated with sevelamer hydrochloride $(-0.48 \pm 2.58 \mathrm{mg} / \mathrm{dL}$ from a baseline value of $1.53 \pm 1.93$ $\mathrm{mg} / \mathrm{dL}, P=0.012$ ) one year after the therapy, but no such decrease was detected in those treated with calcium acetate [8]. Navarro-Gonzalez et al. compared the changes in proinflammatory cytokine levels as well as hs-CRP level between HD patients treated with sevelamer hydrochloride and those treated with calcium acetate in a randomized trial [29]. In those treated with sevelamer hydrochloride, serum levels of hs-CRP, interleukin (IL)-6, and soluble CD14 significantly decreased at 3 months after the therapy. Anti-inflammatory IL-10 showed a significant increase. In contrast, the patients treated with calcium acetate showed significantly increased serum IL-6. Multiple regression analysis demonstrated that the change in $\mathrm{Ca} \times \mathrm{P}$ product was an independent predictor of serum IL- 6 , even after adjustment for serum endotoxin level. The authors suggested that control of $\mathrm{Ca} \times \mathrm{P}$ product with sevelamer might be associated with modulation of inflammation [29]. However, the $\mathrm{Ca} \times \mathrm{P}$ products after therapy were almost similar between the sevelamer group and the calcium acetate group $\left(45.3 \pm 11.7 \mathrm{vs} 44.5 \pm 7.8 \mathrm{mg}^{2} / \mathrm{dL}^{2}\right)$. Their speculation seems somewhat questionable. Another speculation of the anti-inflammatory effect of sevelamer is that sevelamer might have a chelation effect on pro-inflammatory compounds in the intestinal lumen $[8,30]$.

Other inflammatory substances reduced by sevelamer include tumor necrosis factor (TNF)- $\alpha[30]$ and endotoxin [29, 31]. It appears that the anti-inflammatory effect of sevelamer leads to increased serum albumin level reported in some studies [28, 30]. In these studies, however, the authors did not mention the change in protein intake after sevelamer administration. Whether sevelamer might increase serum albumin level independently of protein intake remains to be elucidated.

\section{Antioxidant effect}

Oxidative stress is highly prevalent in CKD patients and has been linked to several surrogate markers of atherosclerosis, such as endothelial dysfunction and intima-media thickness [32]. In a randomized trial including $52 \mathrm{HD}$ patients [33], there was a significant decrease in plasma hydrogen peroxide-related radicals detected by chemiluminescence measurement 8 weeks after the therapy in the sevelamer group $(P<0.001)$, but not in the calcium acetate group. In another randomized study including 31 HD patients, Peres et al. detected a significant decrease in in vitro reactive oxygen species production 12 months after sevelamer therapy [30]. Furthermore, in an intention-to-treat crossover study including 20 diabetic patients with CKD stage 2-4, Vlassara et al. found that those treated with sevelamer demonstrated decreased level of 8-isoprostanes [34]. Future studies including a larger number of patients are required to confirm the antioxidant effect of sevelamer.

\section{Effect on fetuin-A}

Fetuin-A has been noted as a vascular calcification inhibitor and is associated with mortality in HD patients [35]. Brandenburg et al. examined the effect of sevelamer on fetuin-A level in a prospective study with an intention-to-treat analysis including 57 HD patients [28]. After phosphate binder was changed from calcium-containing binder to sevelamer hydrochloride, serum fetuin-A level significantly increased (+21\%). Lower sevelamer dose was associated with lower serum fetuin-A level compared with higher sevelamer dose $(P<$ 0.05). Cagler et al. showed that in an 8-week randomized study including 50 non-diabetic patients with CKD stage 4, sevelamer induced a significant increase in serum fetuin-A level 


\section{Kidney Blood Pressure Research}

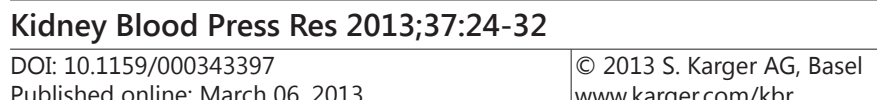

www.karger.com/kbr

Ikee/Tsunoda/Sasaki/Sato/Hashimoto: Emerging Effects of Sevelamer

along with improved endothelial dysfunction detected by flow-mediated dilation [12]. This effect was not observed in those treated with calcium acetate. Further studies should confirm these observations, but the relationship between sevelamer and fetuin-A seems fascinating.

\section{Anemia control}

In CKD patients, anemia is another important complication associated with decreased quality of life and cardiovascular morbidity and mortality [36, 37]. Erythropoiesisstimulating agents (ESA) play a pivotal role in the management of renal anemia. Recently, we reported an independent association between sevelamer dose and ESA responsiveness in a cross-sectional study including 45 HD patients [38]. In this study, higher sevelamer hydrochloride dose was independently associated with ESA responsiveness $(P=0.002)$, even after adjustment for male sex, hs-CRP level, transferrin saturation rate, and VDRA dose. Our findings are supported by subsidiary results of a recent study by Panichi et al. including 653 HD patients [39]. In their study, the proportion of patients treated with sevelamer differed significantly between the lowest and the highest ESA resistance quartiles $(36.4 \%$ vs $18.5 \%, P=0.001$ ) and multivariate analysis demonstrated an independent association between sevelamer use and the lowest ESA resistance quartile $(P<0.001)$. The mechanisms responsible for these results remain to be elucidated, but the decreases in serum levels of certain cytokines, such as IL- 6 and TNF- $\alpha[29,30]$, might improve anemia, as these cytokines are known to interfere with erythropoiesis [40].

In contrast, some studies reported a decrease in serum folic acid level by sevelamer [41, 42], which might exacerbate anemia. Schiffl et al. showed a significant decrease in serum folic acid level (from $12 \pm 5$ to $8 \pm 3 \mathrm{ng} / \mathrm{mL}, P<0.05$ ) and an increase in ESA dose (from $52 \pm$ 9 to $68 \pm 15 \mathrm{IU} / \mathrm{kg} /$ week, $P<0.05$ ) at 1 year after sevelamer therapy in $19 \mathrm{HD}$ patients [42].

Only limited data are available on the relationship between sevelamer and anemia. Randomized controlled trials are required to investigate the causal relationship between sevelamer and ESA responsiveness.

\section{Effect on advanced glycation end products}

In a 12-month randomized trial including $183 \mathrm{HD}$ patients, Kakuta et al. compared the change in plasma pentosidine level between the patients treated with sevelamer hydrochloride and those treated with calcium carbonate [9]. After the therapy, the calcium carbonate group showed significantly increased plasma pentosidine level (from $1.845 \pm$ 0.907 to $2.121 \pm 0.930 \mathrm{nmol} / \mathrm{mL}, P<0.001$ ), but the sevelamer group did not (from $1.861 \pm$ 0.761 to $1.882 \pm 0.860 \mathrm{nmol} / \mathrm{mL}, P=0.6$ ). In addition, Vlassara et al. examined the changes in plasma levels of advanced glycation end products (AGE) in diabetic patients with CKD stage 2-4 in an intention-to-treat crossover study [34]. Compared with calcium carbonate, sevelamer carbonate decreased serum methylglyoxal and ${ }^{\varepsilon} \mathrm{N}$-carboxymethyl-lysine. Thus, the relationship between sevelamer and AGE is worthy of further study.

\section{Effect on trace element metabolism}

In an in vitro study, Takagi et al. found that sevelamer hydrochloride adsorbed $\mathrm{Cu}^{2+}$ and $\mathrm{Zn}^{2+}$, particularly at acid $\mathrm{pH}$ [43]. In our recent cross-sectional study, sevelamer hydrochloride dose inversely correlated with serum copper level in HD patients [44]. Veighey et al. compared serum levels of zinc, copper, and selenium between HD patients treated with sevelamer hydrochloride and those treated with calcium- or lanthanum-containing phosphate binder [45]. As a result, there was no difference in all of these trace element levels.

Some studies have suggested associations between trace element metabolism and 


\section{Kidney \\ Blood Pressure Research}

inflammation, oxidative stress, or atherosclerosis in HD patients [44, 46, 47]. The effect of sevelamer on trace element metabolism should be examined by further studies.

\section{Clinically-relevant side effects}

As mentioned above, sevelamer has been suggested to have many favorable pleiotropic effects. However, some characteristics of sevelamer, such as lower adsorbing capacity for phosphorus and higher incidence of gastrointestinal symptoms $[48,49]$ should be improved. In addition, unfavorable effects might occur through its adsorption of various substances, such as folic acid. In addition, serum levels of uremic toxins such as indoxyl sulphate, indole acetic acid, and hippuric acid were not improved by sevelamer administration $[28,41]$.

Sevelamer hydrochloride can also exacerbate metabolic acidosis. Sevelamer hydrochloride acts like an ion-exchange resin in the gastrointestinal tract and releases one mole of chloride for every mole of phosphorus that it binds to. The released chloride is buffered by bicarbonate, which leads to reduced serum bicarbonate level, and hence, metabolic acidosis. Metabolic acidosis is an important problem of CKD and is associated with increased protein catabolism, insulin resistance, systemic inflammation, bone disease, and probably increased serum $\beta_{2}$-microglobulin [50]. However, sevelamer carbonate, another salt of sevelamer, might solve this problem. Fan et al. recently showed that sevelamer carbonate well controlled hyperphosphatemia and increased serum bicarbonate level [51]. Although the data on pleiotropic effects of sevelamer carbonate are limited, the effect on AGE has been reported in the aforementioned study by Vlassara et al. [34].

\section{Comparison with lanthanum carbonate}

Lanthanum carbonate is another calcium-free phosphate binder. Two crossover studies compared phosphorus-lowering effects between sevelamer hydrochloride and lanthanum carbonate, and reported no difference in serum phosphorus levels at an adequate prescribed dose $[49,52]$. As reported in the previous studies, lanthanum carbonate would show a favorable effect on metabolic acidosis [53] and an unfavorable effect on lipid profiles compared with sevelamer hydrochloride [45]. Nikolov et al. examined vascular calcification in uremic apolipoprotein E-deficient mice [54], and both drugs suppressed the progression of vascular calcification. Their data regarding oxidative stress and bone formation suggested that this vascular protective effect would result from different mechanisms between the drugs.

The calcium-free nature of lanthanum carbonate seems beneficial, but clinicians should pay an attention to the fact that the safety of lanthanum administration has not been ascertained after a long-term use for more than 10-20 years.

\section{Conclusion}

Sevelamer with various pleiotropic effects seems a promising agent in CKD patients, but its effect on mortality is not conclusive. Further studies are required to clearly show the beneficial effects. As sevelamer hydrochloride improved vascular calcification and mortality in incident HD patients [7, 17], sevelamer administration in an early phase of CKD/ESRD might be required to improve patient's prognosis. In addition, the benefit of sevelamer hydrochloride might be concealed by metabolic acidosis exacerbated by the drug itself. Sevelamer carbonate might more evidently demonstrate beneficial effects.

\section{Conflict of Interests}

None to declare. 


\section{Kidney \\ Blood Pressure Research}

\begin{tabular}{l|l}
\hline \multicolumn{2}{l}{ Kidney Blood Press Res 2013;37:24-32 } \\
\hline DOI: $10.1159 / 000343397$ & $\begin{array}{l}\text { C } 2013 \text { S. Karger AG, Basel } \\
\text { www.karger.com/kbr }\end{array}$ \\
\hline $\begin{array}{ll}\text { Published onlIne: March 06, } 2013 & \end{array}$
\end{tabular}

Ikee/Tsunoda/Sasaki/Sato/Hashimoto: Emerging Effects of Sevelamer

\section{References}

1 Kalantar-Zadeh K, Shah A, Duong U, Hechter RC, Dukkipati R, Kovesdy CP: Kidney bone disease and mortality in CKD: revisiting the role of vitamin D, calcimimetics, alkaline phosphatase, and minerals. Kidney Int 2010;78:S10-S21.

2 Patel T, Singh AK: Role of vitamin D in chronic kidney disease. Semin Nephrol 2009;29:113-121.

-3 Chertow GM, Burke SK, Lazarus JM, Stenzel KH, Wombolt D, Goldberg D, Bonventre JV, Slatopolsky E: Poly[allylamine hydrochloride] (RenaGel): a noncalcemic phosphate binder for the treatment of hyperphosphatemia in chronic renal failure. Am J Kidney Dis 1997;29:66-71.

4 Bleyer AJ, Burke SK, Dillon M, Garrett B, Kant KS, Lynch D, Rahman SN, Schoenfeld P, Teitelbaum I, Zeig S, Slatopolsky E: A comparison of the calcium-free phosphate binder sevelamer hydrochloride with calcium acetate in the treatment of hyperphosphatemia in hemodialysis patients. Am J Kidney Dis 1999;33:694701.

5 Chertow GM, Burke SK, Raggi P; Treat to Goal Working Group: Sevelamer attenuates the progression of coronary and aortic calcification in hemodialysis patients. Kidney Int 2002;62:245-252.

6 Asmus HG, Braun J, Krause R, Brunkhorst R, Holzer H, Schulz W, Neumayer HH, Raggi P, Bommer J: Two year comparison of sevelamer and calcium carbonate effects on cardiovascular calcification and bone density. Nephrol Dial Transplant 2005;20:1653-1661.

7 Block GA, Spiegel DM, Ehrlich J, Mehta R, Lindbergh J, Dreisbach A, Raggi P: Effects of sevelamer and calcium on coronary artery calcification in patients new to hemodialysis. Kidney Int 2005;68:1815-1824.

-8 Ferramosca E, Burke S, Chasan-Taber S, Ratti C, Chertow GM, Raggi P. Potential antiatherogenic and antiinflammatory properties of sevelamer in maintenance hemodialysis patients. Am Heart J 2005;149:820825 .

-9 Kakuta T, Tanaka R, Hyodo T, Suzuki H, Kanai G, Nagaoka M, Takahashi H, Hirawa N, Oogushi Y, Miyata T, Kobayashi H, Fukagawa M, Saito A: Effect of sevelamer and calcium-based phosphate binders on coronary artery calcification and accumulation of circulating advanced glycation end products in hemodialysis patients. Am J Kidney Dis 2011;57:422-431.

10 Raggi P, Bommer J, Chertow GM: Valvular calcification in hemodialysis patients randomized to calciumbased phosphorus binders or sevelamer. J Heart Valve Dis 2004;13:134-141.

11 Yilmaz MI, Sonmez A, Saglam M, Yaman H, Kilic S, Eyileten T, Caglar K, Oguz Y, Vural A, Yenicesu M, Mallamaci F, Zoccali C: Comparison of calcium acetate and sevelamer on vascular function and fibroblast growth factor 23 in CKD patients: a randomized clinical trial. Am J Kidney Dis 2012;59:177-185.

12 Caglar K, Yilmaz MI, Saglam M, Cakir E, Acikel C, Eyileten T, Yenicesu M, Oguz Y, Vural A, Carrero JJ, Axelsson J, Lindholm B, Stenvinkel P: Short-term treatment with sevelamer increases serum fetuin-a concentration and improves endothelial dysfunction in chronic kidney disease stage 4 patients. Clin J Am Soc Nephrol 2008;3:61-68.

13 Boaz M, Katzir Z, Schwartz D, Gafter U, Biro A, Shtendik L, Kon V, Chernin G, Weinstein T: Effect of sevelamer hydrochloride exposure on carotid intima media thickness in hemodialysis patients. Nephrol Clin Pract 2011;117:c83-c88.

-14 Iimori S, Mori Y, Akita W, Takada S, Kuyama T, Ohnishi T, Shikuma S, Ishigami J, Tajima M, Asai T, Okado T, Kuwahara M, Sasaki S, Tsukamoto Y: Effects of sevelamer hydrochloride on mortality, lipid abnormality and arterial stiffness in hemodialyzed patients: a propensity-matched observational study. Clin Exp Nephrol 2012;16:930-937.

15 Barreto DV, Barreto Fde C, de Carvalho AB, Cuppari L, Draibe SA, Dalboni MA, Moyses RM, Neves KR, Jorgetti V, Miname M, Santos RD, Canziani ME: Phosphate binder impact on bone remodeling and coronary calcification - results from the BRiC study. Nephron Clin Pract 2008;110:c273-c283.

16 Qunibi W, Moustafa M, Muenz LR, He DY, Kessler PD, Diaz-Buxo JA, Budoff M, CARE-2 Investigators: A 1-year randomized trial of calcium acetate versus sevelamer on progression of coronary artery calcification in hemodialysis patients with comparable lipid control: the Calcium Acetate Renagel Evaluation-2 (CARE2) study. Am J Kidney Dis 2008;51:952-965.

17 Block GA, Raggi P, Bellasi A, Kooienga L, Spiegel DM: Mortality effect of coronary calcification and phosphate binder choice in incident hemodialysis patients. Kidney Int 2007;71:438-441.

$\checkmark 18$ Borzecki AM, Lee A, Wang SW, Brenner L, Kazis LE: Survival in end stage renal disease: calcium carbonate vs. sevelamer. J Clin Pharm Ther 2007;32:617-624. 


\section{Kidney \\ Blood Pressure Research}

\begin{tabular}{l|l}
\hline Kidney Blood Press Res 2013;37:24-32 \\
\hline DOI: $10.1159 / 000343397$ & (c) 2013 S. Karger AG, Basel
\end{tabular}

Published onlıne: March 06, 2013

www.karger.com/kbr

Ikee/Tsunoda/Sasaki/Sato/Hashimoto: Emerging Effects of Sevelamer

19 Suki WN, Zabaneh R, Cangiano JL, Reed J, Fischer D, Garrett L, Ling BN, Chasan-Taber S, Dillon MA, Blair AT, Burke SK: Effects of sevelamer and calcium-based phosphate binders on mortality in hemodialysis patients. Kidney Int 2007;72:1130-1137.

-20 St Peter WL, Liu J, Weinhandl E, Fan Q: A comparison of sevelamer and calcium-based phosphate binders on mortality, hospitalization, and morbidity in hemodialysis: a secondary analysis of the Dialysis Clinical Outcomes Revisited (DCOR) randomized trial using claims data. Am J Kidney Dis 2008;51:445-454.

21 Di Iorio B, Bellasi A, Russo D, INDEPENDENT Study Investigators: Mortality in kidney disease patients treated with phosphate binders: a randomized study. Clin J Am Soc Nephrol 2012;7:487-493.

-22 Raggi P, James G, Burke SK, Bommer J, Chasan-Taber S, Holzer H, Braun J, Chertow GM: Decrease in thoracic vertebral bone attenuation with calcium-based phosphate binders in hemodialysis. J Bone Miner Res 2005;20:764-772.

-23 Ferreira A, Frazao JM, Monier-Faugere MC, Gil C, Galvao J, Oliveira C, Baldaia J, Rodrigues I, Santos C, Ribeiro S, Hoenger RM, Duggal A, Malluche HH, Sevelamer Study Group: Effects of sevelamer hydrochloride and calcium carbonate on renal osteodystrophy in hemodialysis patients. J Am Soc Nephrol 2008;19:405-412.

24 Negishi K, Kobayashi M, Ochiai I, Yamazaki Y, Hasegawa H, Yamashita T, Shimizu T, Kasama S, Kurabayashi M: Association between fibroblast growth factor 23 and left ventricular hypertrophy in maintenance hemodialysis patients. Comparison with B-type natriuretic peptide and cardiac troponin T. Circ J 2010;74:2734-2740.

25 Gutierrez OM, Mannstadt M, Isakova T, Rauh-Hain JA, Tamez H, Shah A, Smith K, Lee H, Thadhani R, Juppner $\mathrm{H}$, Wolf M: Fibroblast growth factor 23 and mortality among patients undergoing hemodialysis. N Engl J Med 2008;359:584-592.

26 Faul C, Amaral AP, Oskouei B, Hu MC, Sloan A, Isakova T, Gutierrez OM, Aguillon-Prada R, Lincoln J, Hare JM, Mundel P, Morales A, Scialla J, Fischer M, Soliman EZ, Chen J, Go AS, Rosas SE, Nessel L, Townsend RR, Feldman HI, St John Sutton M, Ojo A, Gadegbeku C, Di Marco GS, Reuter S, Kentrup D, Tiemann K, Brand M, Hill JA, Moe OW, Kuro-O M, Kusek JW, Keane MG, Wolf M: FGF23 induces left ventricular hypertrophy. J Clin Invest 2011;121:4393-4408.

27 Oliveira RB, Cancela AL, Graciolli FG, Dos Reis LM, Draibe SA, Cuppari L, Carvalho AB, Jorgetti V, Canziani ME, Moyses RM: Early control of PTH and FGF23 in normophosphatemic CKD patients: a new target in CKD-MBD therapy? Clin J Am Soc Nephrol 2010;5:286-291.

28 Brandenburg VM, Schlieper G, Heussen N, Holzmann S, Busch B, Evenepoel P, Vanholder R, Meijers B, Meert N, Fassbender WJ, Floege J, Jahnen-Dechent W, Ketteler M: Serological cardiovascular and mortality risk predictors in dialysis patients receiving sevelamer: a prospective study. Nephrol Dial Transplant 2010;25:2672-2679.

29 Navarro-Gonzalez JF, Mora-Fernandez C, Muros de Fuentes M, Donate-Correa J, Cazana-Perez V, GarciaPerez J: Effect of phosphate binders on serum inflammatory profile, soluble CD14, and endotoxin levels in hemodialysis patients. Clin J Am Soc Nephrol 2011;6:2272-2279.

-30 Peres AT, Dalboni MA, Canziani ME, Manfredi SR, Carvalho JT, Batista MC, Cuppari L, Carvalho AB, Moyses RM, Guimaraes N, Jorgetti V, Andreoli MC, Draibe SA, Cendoroglo M: Effect of phosphate binders on oxidative stress and inflammation markers in hemodialysis patients. Hemodial Int 2009;13:271-277.

-31 Sun PP, Perianayagam MC, Jaber BL: Sevelamer hydrochloride use and circulating endotoxin in hemodialysis patients: a pilot cross-sectional study. J Ren Nutr 2009;19:432-438.

-32 Del Vecchio L, Locatelli F, Carini M: What we know about oxidative stress in patients with chronic kidney disease on dialysis--clinical effects, potential treatment, and prevention. Semin Dial 2011;24:56-64.

-33 Lin YF, Chien CT, Kan WC, Chen YM, Chu TS, Hung KY, Tsai TJ, Wu KD, Wu MS: Pleiotropic effects of sevelamer beyond phosphate binding in end-stage renal disease patients: a randomized, open-label, parallel-group study. Clin Drug Investig 2011;31:257-267.

34 Vlassara H, Uribarri J, Cai W, Goodman S, Pyzik R, Post J, Grosjean F, Woodward M, Striker GE: Effects of sevelamer on $\mathrm{HbA1c}$, inflammation, and advanced glycation end products in diabetic kidney disease. Clin J Am Soc Nephrol 2012;7:934-942.

-35 Hermans MM, Brandenburg V, Ketteler M, Kooman JP, van der Sande FM, Boeschoten EW, Leunissen KM, Krediet RT, Dekker FW; Netherlands cooperative study on the adequacy of Dialysis (NECOSAD): Association of serum fetuin-A levels with mortality in dialysis patients. Kidney Int 2007;72:202-207.

-36 Portoles J, Lopez-Gomez JM, Aljama PA: A prospective multicentre study of the role of anaemia as a risk factor in haemodialysis patients: the MAR Study. Nephrol Dial Transplant 2007;22:500-507. 


\section{Kidney \\ Blood Pressure Research}

Kidney Blood Press Res 2013;37:24-32

\begin{tabular}{l|l}
\hline DOI: $10.1159 / 000343397$ & (C) 2013 S. Karger AG, Basel
\end{tabular}

www.karger.com/kbr

Ikee/Tsunoda/Sasaki/Sato/Hashimoto: Emerging Effects of Sevelamer

-37 Akizawa T, Pisoni RL, Akiba T, Saito A, Fukuhara S, Asano Y, Hasegawa T, Port FK, Kurokawa K: Japanese haemodialysis anaemia management practices and outcomes (1999-2006): results from the DOPPS. Nephrol Dial Transplant 2008;23:3643-3653.

-38 Ikee R, Tsunoda M, Sasaki N, Sato N, Hashimoto N: Potential influence of sevelamer hydrochloride on responsiveness to erythropoiesis-stimulating agents in haemodialysis patients. Nephrology (Carlton) 2012;17:225-229.

-39 Panichi V, Rosati A, Bigazzi R, Paoletti S, Mantuano E, Beati S, Marchetti V, Bernabini G, Grazi G, Rizza GM, Migliori M, Giusti R, Lippi A, Casani A, Barsotti G, Tetta C, RISCAVID Study Group: Anaemia and resistance to erythropoiesis-stimulating agents as prognostic factors in haemodialysis patients: results from the RISCAVID study. Nephrol Dial Transplant 2011;26:2641-2648.

40 Weiss G, Gooodnough LT: Anemia of chronic disease. N Engl J Med 2005;352:1011-1023.

41 Goto S, Yoshiya K, Kita T, Fujii H, Fukagawa M: Uremic toxins and oral adsorbents. Ther Apher Dial 2011;15:132-134.

42 Schiffl H, Lang SM: Phosphate binder is not phosphate binder! Sevelamer may be different! Nephrol Dial Transplant 2011;26:377-378.

43 Takagi K, Masuda K, Yamazaki M, Kiyohara C, Itoh S, Wasaki M, Inoue H: Metal ion and vitamin adsorption profiles of phosphate binder ion-exchange resins. Clin Nephrol 2010;73:30-35.

44 Ikee R, Tsunoda M, Sasaki N, Sato N, Hashimoto N: Clinical factors associated with serum copper levels and potential effect of sevelamer in hemodialysis patients. Int Urol Nephrol DOI: 10.1007/s11255-012-0211-3.

45 Veighey K, Booth J, Davenport A: Does the choice of phosphate binder affect trace element levels in chronic kidney disease patients treated by regular haemodialysis? Nephrol Dial Transplant 2011;26:1006-1010.

-46 Koca T, Berber A, Koca HB, Demir TA, Koken T: Effects of hemodialysis period on levels of blood trace elements and oxidative stress. Clin Exp Nephrol 2010;14:463-468.

47 Ari E, Kaya Y, Demir H, Asicioglu E, Keskin S: The correlation of serum trace elements and heavy metals with carotid artery atherosclerosis in maintenance hemodialysis patients. Biol Trace Elem Res 2011;144:351-359.

48 Koiwa F, Onoda N, Kato H, Tokumoto A, Okada T, Fukagawa M, Shigematsu T, ROD 21 Clinical Research Group: Prospective randomized multicenter trial of sevelamer hydrochloride and calcium carbonate for the treatment of hyperphosphatemia in hemodialysis patients in Japan. Ther Apher Dial 2005;9:340-346.

49 Kasai S, Sato K, Murata Y, Kinoshita Y: Randomized crossover study of the efficacy and safety of sevelamer hydrochloride and lanthanum carbonate in Japanese patients undergoing hemodialysis. Ther Apher Dial 2012;16:341-349.

50 Sonikian M, Gogusev J, Zingraff J, Loric S, Quednau B, Bessou G, Siffert W, Drueke TB, Reusch HP, Luft FC: Potential effect of metabolic acidosis on beta 2-microglobulin generation: in vivo and in vitro studies. J Am Soc Nephrol 1996;7:350-356.

-51 Fan S, Ross C, Mitra S, Kalra P, Heaton J, Hunter J, Plone M, Pritchard N: A randomized, crossover design study of sevelamer carbonate powder and sevelamer hydrochloride tablets in chronic kidney disease patients on haemodialysis. Nephrol Dial Transplant 2009;24:3794-3799.

52 Sprague SM, Ross EA, Nath SD, Zhang P, Pratt RD, Krause R: Lanthanum carbonate vs. sevelamer hydrochloride for the reduction of serum phosphorus in hemodialysis patients: a crossover study. Clin Nephrol 2009;72:252-258.

53 Chan WL, Rounsley K, Chapman E, Collings K, Dale C, De Waal S, Patel V, Tanner J, Turner E, Moore J, Borrows R: Lanthanum carbonate is an effective hypophosphatemic agent for hemodialysis patients intolerant of other phosphate binders. J Ren Nutr 2010;20:270-277.

54 Nikolov IG, Joki N, Nguyen-Khoa T, Guerrera IC, Maizel J, Benchitrit J, Machado dos Reis L, Edelman A, Lacour B, Jorgetti V, Drueke TB, Massy ZA: Lanthanum carbonate, like sevelamer-HCl, retards the progression of vascular calcification and atherosclerosis in uremic apolipoprotein E-deficient mice. Nephrol Dial Transplant 2012;27:505-513. 